\title{
Accuracy of physical examination versus ultrasound in the detection of hepatosplenomegaly at diagnosis of pediatric leukemia
}

\author{
Janelle Cyr, Donna L. Johnston \\ Division of Hematology/Oncology, Children's Hospital of Eastern Ontario, Ottawa, Ontario, Canada
}

Correspondence: Donna Johnston. Address: Children's Hospital of Eastern Ontario, 401 Smyth Road, Ottawa, Ontario, K1H 8L1, Canada. Email: djohnston@cheo.on.ca

Received: December 17, 2012

DOI : $10.5430 / j h m . v 3 n 1 p 24$
Accepted: February 17, 2013

URL: http://dx.doi.org/10.5430/jhm.v3n1p24

\section{Abstract}

Background: Hepatosplenomegaly (HSM) is common at diagnosis of pediatric leukemia and is diagnosed through palpation or ultrasound. We sought to determine if ultrasound was necessary.

Methods: Spleen and liver size was recorded from palpation and ultrasound for 94 children with a new diagnosis of leukemia.

Results: Palpation was correct in detecting 71\% (173/245) of cases of splenomegaly and 68\% (172/254) of cases of hepatomegaly. There was no relationship between body mass index and clinician accuracy at diagnosis of HSM. Ultrasound examination had abnormal findings excluding HSM in 56\% of patients.

Conclusions: Ultrasound examination is a warranted investigation for newly diagnosed children with leukemia.

\section{Key words}

Hepatosplenomegaly, Leukemia, Ultrasound

\section{Introduction}

Hepatomegaly and splenomegaly (HSM) are commonly present at diagnosis of pediatric leukemia and are attributed to the collection of leukemia cells in these organs. The presence or absence of hepatosplenomegaly has been shown to affect prognosis in some types of leukemia such as AML, JMML, and patients with Down syndrome ${ }^{[1-3]}$. HSM can be diagnosed through physician examination or ultrasound (US) and is routinely tested for at diagnosis. Hepatomegaly and splenomegaly can be diagnosed with physical examination and this can be confirmed with ultrasound (US) imaging, which is regarded as the best method to document the size of these organs ${ }^{[4-7]}$. HSM is routinely tested for at diagnosis of leukemia. There is very little in the literature in pediatric or adult medicine about the accuracy of physical examination for the detection of hepatosplenomegaly. However, comparing physical accuracy to medical imaging tests has been examined for other issues ${ }^{[8-12]}$. 
At some centers it is common practice to perform ultrasound in addition to examination in order to diagnose HSM; we sought to determine if this was necessary or if it was diagnosed accurately with physical examination alone.

\section{Methods}

A retrospective chart review was done assessing HSM in 94 consecutive children with a new diagnosis of leukemia over the last five years at the Children's Hospital of Eastern Ontario (CHEO). CHEO is a tertiary care academic pediatric centre. Inclusion criteria were a leukemia diagnosis in the past 5 years and age less than 18 at the time of diagnosis. Exclusion criteria were no US done for the patient. Admission location, weight and height were recovered for all children. Size of spleen and liver (enlarged vs normal) through physical examination was recorded from physician notes in the emergency department and upon admission to the ward, and level of training of the person examining the patient was taken for each finding. Ultrasound documentation of enlargement was considered positive if the chart stated "enlarged", "palpable spleen", "liver below costal margin", or any other statement indicating enlargement. Examination findings were compared to US findings for confirmation of the presence of hepatosplenomegaly through descriptive analysis. Results of examination detection accuracy were also examined against level of staff to determine any patterns in ability to detect HSM. Statistical analysis was done using SPSS version 19. The CHEO Research Ethics Board approved the study.

\section{Results}

During the study time period, 94 children with leukemia had documented physical examinations at diagnosis performed in 245 cases for splenomegaly and in 254 cases for hepatomegaly. These children also had abdominal/pelvic US performed at diagnosis. This ultrasound took place a median of 3 days after physical examination (range 0-9 days). When compared to the US results documenting the organ size, physical examination was correct in detecting $71 \%$ (173/245) of cases of splenomegaly and 68\% (172/254) of cases of hepatomegaly (see Table 1). Splenomegaly was undercalled (physical exam noted as normal and US documented enlarged) in 25\% (61/245) of examinations. It was overcalled (physical exam noted as enlarged and US examination normal) in 4\% (10/245) of examinations. Hepatomegaly was undercalled in 19\% (48/254) of examinations, and it was overcalled in $13 \%$ (33/254) of cases.

Table 1. Hepatosplenomegaly detection rates

\begin{tabular}{|c|c|c|c|c|c|c|}
\hline & & $\begin{array}{l}\text { Medical } \\
\text { student }\end{array}$ & Resident & Staff & Undercalled & Overcalled \\
\hline \multirow[t]{2}{*}{ Splenomegaly } & Number & 36 & 139 & 70 & 61 & 10 \\
\hline & Correct & 19 & 113 & 55 & & \\
\hline \multirow[t]{2}{*}{ Hepatomegaly } & Number & 35 & 147 & 72 & 48 & 33 \\
\hline & Correct & 15 & 107 & 49 & & \\
\hline
\end{tabular}

Undercalled -physical exam noted as normal and ultrasound documented enlarged

Overcalled -physical exam noted as enlarged and ultrasound documented normal

Fifty-six percent (53/94) of patients with abdominal/pelvic US results had abnormal findings excluding HSM. These other findings included excess free fluid (24\%), enlarged kidneys (19\%), enlarged lymph nodes (18\%), pleural effusion (6\%), enlarged gallbladder wall (6\%), enlarged pancreas (4\%), enlarged appendix (2\%), enlarged uterus (2\%), bowel intussusception (2\%), hydronephrosis (1\%), and thickened peritoneum (1\%).

Body Mass Index (BMI) was calculated for each child and assessed against physical examination to determine if there was a discrepancy in results that was dependent on BMI. There was no relationship between high BMI (greater than 18.5), or normal/low BMI (less than 18.5) and physician accuracy at diagnosis of HSM. In patients with high BMI, the detection of both hepatomegaly and splenomegaly was accurate in 17\% (14/83) of the cases. In patients with low BMI, 13\% (21/163) 
were detected accurately for both hepatomegaly and splenomegaly. Age and gender were also assessed against physical examination to determine if there was a discrepancy in results that was dependent on these variables. Again, no significant difference was noted for either age of the patient or gender in the detection of hepatosplenomegaly.

As previously reported ${ }^{[13]}$ comparisons were made between level of physical examiner and accuracy of detection. Splenomegaly was correctly diagnosed by medical students $54 \%$ of the time, by residents $81 \%$, and by staff $79 \%$ of the time. First year residents diagnosed it correctly $68 \%$ of the time, second year $64 \%$, third year $76 \%$ and forth year $86 \%$ of the time. Hepatomegaly was correctly diagnosed by medical students $44 \%$ of the time, residents $73 \%$ and by staff $68 \%$ of the time. First year residents diagnosed it correctly $77 \%$ of the time, second year $54 \%$, third year $81 \%$ and forth year $75 \%$ of the time.

In terms of location of diagnosis, splenomegaly was correctly diagnosed $76 \%(65 / 85)$ of the time in the emergency department and $69 \%$ (112/163) of the time on the inpatient unit. Hepatomegaly was correctly diagnosed 67\% (58/87) of the time in the emergency department and 70\% (117/168) of the time on the inpatient unit.

\section{Discussion}

Not all pediatric facilities in North America perform routine ultrasounds on patients newly diagnosed with leukemia, however the data in this study shows that clinicians are not accurate enough at diagnosing HSM to justify elimination of this radiological examination if clinicians feel that it is important to document HSM or if this information is being collected for study purposes. A significant proportion of cases of HSM were not detected by physical examination at diagnosis of leukemia, only by US examination. Importantly as well, the majority of patients with newly diagnosed leukemia had abnormal US result aside from HSM including ascites, free fluid in the abdomen, enlarged organs, and other potentially significant abnormalities. Many of these findings were clinically very significant.

HSM is common in children with new diagnosis of leukemia, there are instances such as JMML, and patients with Down syndrome where the presence of HSM can affect prognosis ${ }^{[1,3]}$. Other studies exploring the accuracy of physical examination in detecting metatstatic lymphadenopathy in adults have found similar results ${ }^{[14-16]}$. These studies show that palpation has a false-positive rate between $15 \%$ and $65 \%$ and a false negative rate between $10 \%$ and $15 \%$.

In this study, previous examinations of the liver and spleen did not influence the follow up examinations, as inpatient levels of detection were not higher than the detection level in the emergency department, where the patients were initially assessed prior to going to the inpatient unit for assessment. As well, the level of the examiner did not significantly affect the ability to detect HSM, nor did the presence of an elevated body mass index.

This study demonstrates that the practice of performing ultrasound on children with leukemia at diagnosis is a warranted investigation to accurately document HSM and to detect other abnormalities that may be present at diagnosis.

\section{Conflicting interests}

The authors declare that they have no competing interests.

\section{References}

[1] Proytcheva M. Juvenile myelomocytic leukemia. Semin Diagn Pathol. 2011; 28:298-303. PMid:22195407 http://dx.doi.org/10.1053/j.semdp.2011.08.007

[2] Wells RJ, Arthur DC, Srivastava A, et al. Prognostic variables in newly diagnosed children and adolescents with acute myeloid leukemia: Children’s Cancer Group Study 213. Leukemia. 2002; 16:601-7. PMid:11960339

http://dx.doi.org/10.1038/sj.leu.2402390 
[3] Gamis AS, Alonzo TA, Gerbing RB, et al. Natural history of transient myeloproliferative disorder clinically diagnosed in Down syndrome neonates: a report from the Children's Oncology Group Study A2971. Blood. 2011; 118:6752-9. PMid:21849481 http://dx.doi.org/10.1182/blood-2011-04-350017

[4] Lamb PM, Lund A, Kanagasabay RR, et al. Spleen size: how well do linear ultrasound measurements correlate with three-dimensional CT volume assessments. Br J Radiol. 2002; 75:573-77. PMid:12145129

[5] Homeida M, Roberts CJC, Halliwell M, et al. Ultrasonic measurement of liver size. Br Med J. 1976; 2:1561. PMid:1009401 http://dx.doi.org/10.1136/bmj.2.6051.1561-b

[6] Kratzer W, Fritz V, Mason RA, et al. Factors affecting liver size -A sonographic survey of 2080 subjects. J Ultrasound Med, 2003; 22:1155-61. PMid:14620885

[7] Tamayo SG, Rickman LS, Mathews WC, et al. Examiner dependence on physical diagnostic tests for the detection of splenomegaly: A prospective study with multiple observers. J Gen Intern Med. 1993; 8:69-75. PMid:8441078 http://dx.doi.org/10.1007/BF02599986

[8] Prayer L, Winkelbauer H, Gritzmann N, et al. Sonography versus palpation in the detection of regional lymph-node metastases in patients with malignant melanoma. Eur J Cancer. 1990; 26:827-30. http://dx.doi.org/10.1016/0277-5379(90)90163-N

[9] Loose R, Weiss J, Kühn W, et al. Comparison of ultrasound with clinical findings in the early detection of regional metastatic lymph nodes in patients with malignant melanoma. In: Altmeyer P, el Gammal S, Hoffmann K, editors. Ultrasound in Dermatology. Berlin, Heidelberg: Springer Verlag; 1992: 93-9.

[10] Blum A, Carl M, Rassner G. Ultrasound of regional lymph nodes in the follow-up of malignant melanoma. Melanoma Res. 1995; 5:16-7. http://dx.doi.org/10.1097/00008390-199505001-00017

[11] Rossi CR, Seno A, Vecchiato A, et al. The impact of ultrasound scanning in the staging and follow-up of patients with clinical stage I cutaneous melanoma. Eur J Cancer. 1997; 33:200-3. http://dx.doi.org/10.1016/S0959-8049(96)00406-6

[12] Tregnaghi A, De Candia A, Calderone M, et al. Ultrasonographic evaluation of superficial lymph node metastases in melanoma. Eur J Radiol. 1997; 24:216-21. http://dx.doi.org/10.1016/S0720-048X(96)01102-3

[13] Johnston DL, Cyr J. Does Level of Training Influence the Ability to Detect Hepatosplenomegaly in Children with Leukemia?, in press, Can Med Ed J., 2012.

[14] Manfredi D, Jacobelli G. Neck dissection in the treatment of head and neck cancer: Results in 1162 cases, in Chambers RG (ed): Cancer of the Head and Neck. Princeton, NJ, Excerpta Medica. 1975: 221-224.

[15] Martis C, Karabouta I, Lazaridis N. Incidence of lymph node metastasis in elective (prophylactic) neck dissection for oral carcinoma. J Craniomaxillofac Surg. 1979; 7:182-91.

[16] Sako K, Pradier RN, Marchetta FC, et al. Fallibility of palpation in the diagnosis of metastasis to cervical nodes. Surg Gynecol Obstet. 1964; 118:989-90. PMid:14143467 